\title{
High-speed Urbanization and Housing Bubbles
}

\author{
Yao Pang ${ }^{1}$, Yancheng Fan $^{2 *}$, Meng Ye ${ }^{3 *}$ \\ ${ }^{1}$ Institute of Industrial Economics, Chinese Academy of Social Sciences, Beijing, China \\ ${ }^{2}$ School of Economics, Zhejiang University of Finance and Economics, Zhejiang, China \\ ${ }^{3}$ School of Law, China University of Political Science and Law, Beijing, China \\ *Corresponding Author.
}

\begin{abstract}
With China's high-speed urbanization, the housing demands and housing prices have increased rapidly in major cities. By combining the classical bubble theory with investors' short-term decisions, we propose a method to simulate bubbles' rising and bursting process in a multi-sector economy. We find that when urbanization goes too fast, the housing price growth rate will exceed the industrial interest rate, causing enterprises to buy houses. Enterprises' housing investment further increases the expected returns of housing investment, attracting more investment and leads to housing bubbles. The faster the speed of urbanization, the higher the housing price grows, the longer the bubble cycle, and the greater the impact on the economy when bubbles burst. Continued urbanization cannot prevent bubbles from bursting. To ensure economic stability, the pace of urbanization needs to be limited.
\end{abstract}

Keywords: Housing bubbles, adaptive expectations, multi-sector optimization, urbanization

\section{Introduction}

In the past twenty years, with China's economic growth and urbanization, the housing demands and housing prices grow rapidly in major cities. The fast-growing housing prices caused many enterprises to buy houses, and some are only for resale purposes. As corresponding, the growth rate of enterprises' production investment declined sharply (See Figure 1 below).

This unique phenomenon has attracted a lot of attention, and has significant impacts on the economy. Specifically, the slowdown in industrial investment growth has led to a decline in the growth of industrial output and wages. The rise in houses occupied by enterprises has led to a fall in houses occupied by households. Thus, under the goal of maximizing utility, households' saving and consumption decisions will be affected; under the goal of maximizing investment returns, enterprises' production investment and housing investment should reach a balance. Therefore, the multi-sector optimization method should be adopted to analyze bubbles' causes and their influence on the economy. When studying these issues, we found that the current methods have some limitations.

The existing bubble studies can be roughly divided into two categories. The first kind of study analyzes bubbles' characteristics in the steady-state under a multi-sector framework. Representative studies include Grossman and Yanagawa ${ }^{[4]}$, Farhi and Tirole (2012), and Miao and Wang ${ }^{[9]}$ for stock bubbles, Arce and Lopez-Salido ${ }^{[1]}$ and Zhao ${ }^{[12]}$ for housing bubbles. These studies are suitable for long-term bubbles: because the value of bubbles is constant in the steady-state, investors can make accurate and rational expectations, so there will be no short-term snap-ups of assets and sharp increases in asset prices; since this kind of bubbles cannot exist in the infinite rational models (Santos and Woodford ${ }^{[11]}$ ), bubbles' existence and value depend on exogenous variables such as credit constraints and random shocks.

ISSN: 0010-8189

(C) CONVERTER 2020

www.converter-magazine.info 
Another kind of study focus on investors' short-sighted decisions. As the housing bubbles are a low-frequency event, investors are blindly optimistic when housing prices rise (Malpezzi and Wachter ${ }^{[8]}$ ). This optimism increases the demand for houses and exacerbates the housing prices. Until the price growth is lower than expected, investors sell houses, causing bubbles to burst. In these studies, bubble process is endogenous. Representative studies include Herring and Wachter ${ }^{[5]}$, Glaeser et al. ${ }^{[3]}$, etc. But the disadvantage of these studies is that it ignores the consumption of households and the production of firms.

We combine these two kinds of studies and propose a new method to simulate the endogenous evolution of housing bubbles: households choose between goods and houses to maximize utility, while enterprises choose between house investment and production investment to maximize the investment returns. Based on the multisector optimization, agents make short-term decisions through adaptive expectations. Then we use the method to analyze the causes and development of housing bubbles.

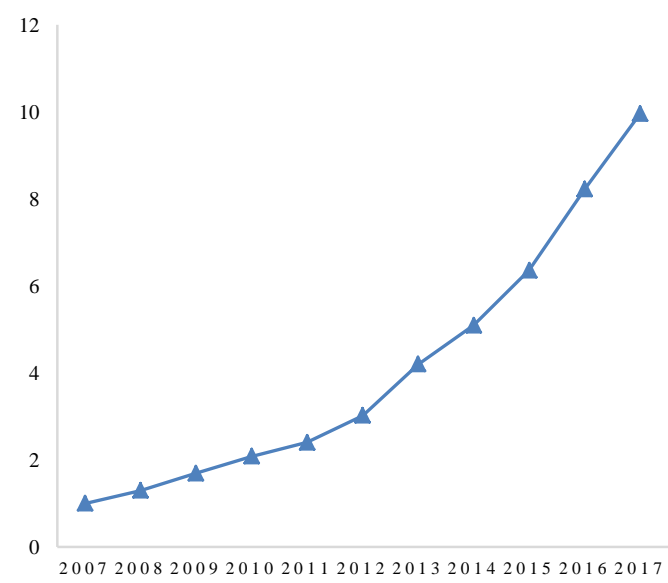

Fig 1.a: Total investment real estate of China's A-share listed companies (hundred billion)

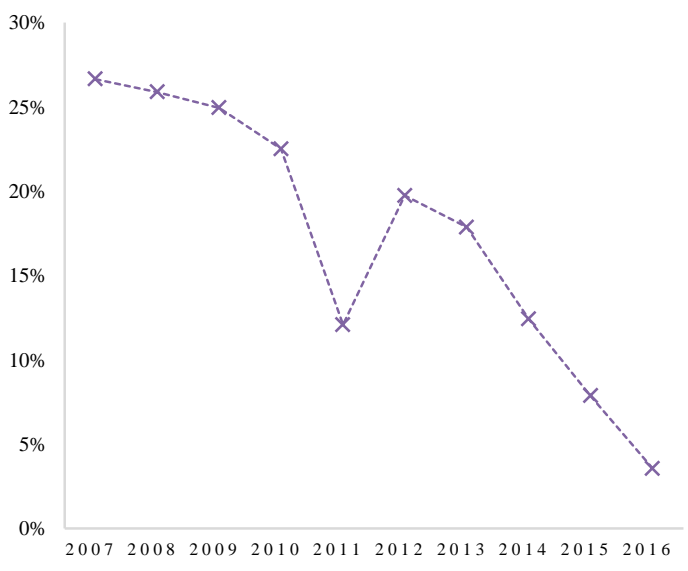

Fig 1.b: Growth rate of industrial fixed asset investment

Data source: Wind

Fig 1: Real estate investment and industrial investment

\section{Benchmark Model}

To make enterprises willing to buy houses, the returns from buying housing are at least equal to the returns from production. But exactly how it happens has not been thoroughly studied. Without enterprises' purchase, housing prices are driven by households' consumption demands, which come from the rise in income and population. Unlike other countries, China's urbanization has a unique characteristic: it is difficult for people outside the cities to get permanent residency and access to urban services, such as education for their children. Buying a house is one way to get urban services. In the urbanization process, many parents buy houses in big cities so that their children can get an education there without moving to work there, which results in a rise in housing demands but an invariant in the number of workers in those cities.

To distinguish these effects, we divide the consumption demand of houses into three categories: 1) the income effect, which means the number of house buyers remains the same, the rising incomes have created more house demand for the constant population. 2) The population effect, which means every family member's housing demand remains the same, and the total population increases, making the number of the labor force and the number of house buyers rises at the same rate. 3) The urbanization effect, which means per capita income and labor force stay constant, but the out-of-town residents' housing demand rises. Then we use the multi-sector model to analyze the three effects.

ISSN: 0010-8189

(C) CONVERTER 2020 


\subsection{Economic description}

The economy is composed of households and enterprises. Drawing on Zhao ${ }^{[12]}$, we set that households derive utility from housing consumption and enterprises buy houses only for resale. Households have workers who earn wages to buy goods and houses, and lack the opportunity for capital investment (Kiyotaki and Moore ${ }^{[7]}$ ). Enterprises have capital, and hire workers to produce goods, and obtain capital gains for goods consumption and capital investment. The total quantity of houses $(H)$ is constant, and each new member of households will share the goods and houses equally with the existing family members.

Final goods are competitive, used for consumption and capital investment, and serve as unit price, with the production function:

$$
Y_{t}=A_{t}\left(K_{t}\right)^{\alpha}\left(L_{t}\right)^{1-\alpha}
$$

where technology $\left(A_{t}\right)$ and labor $\left(L_{t}\right)$ grow exogenously. At the beginning of each period, an enterprise can choose to invest in house purchases or production (Miao \& Wang ${ }^{[9]}$ ). We denote $H K_{t}$ for house purchases and $I K_{t}$ for production, and the total capital is $O K_{t}=I K_{t}+H K_{t}\left(H K_{t}, I K_{t} \geq 0\right)$. Enterprises' objective function and budget constraints are respectively:

$$
\begin{gathered}
\operatorname{Max} \sum_{t=0}^{\infty} \beta^{t} \cdot \ln C_{e, t} \\
\text { S.t. }\left\{\begin{array}{c}
r_{t}\left(O K_{t}-H K_{t}\right)-C_{e, t}-I_{t}=0 \\
H K_{t}-P_{t}\left(H_{e, t}-H_{e, t-1}\right)=0 \\
O K_{t+1}-I_{t}=0
\end{array}\right.
\end{gathered}
$$

where $C_{e, t}$ is enterprises' consumption, $H_{e, t}$ is the houses held by enterprises, $P_{t}$ is the housing price, $I_{t}$ is the capital investment at the end of the period, and $r_{t}$ is the interest rate. The first-order conditions are:

$$
\begin{gathered}
\frac{P_{t+1}}{P_{t}}=r_{t} \\
\frac{C_{e, t+1}}{C_{e, t}}=\beta r_{t+1}
\end{gathered}
$$

Equation (6) shows that to make enterprises willing to hold houses, the housing price growth rate must equal the interest rate.

Households can sell their houses at the beginning of each period, and spend the money along with wages for consumption. The households' optimization problem is:

$$
\begin{gathered}
\operatorname{Max} \sum_{t=0}^{\infty} \beta^{t}\left(\ln C_{h, t}+j_{t} \cdot \ln H_{h, t}\right) \\
\text { S.t. } P_{t}\left(H_{h, t-1}-H_{h, t}\right)+w_{t} L_{t}-C_{h, t}=0
\end{gathered}
$$

where $C_{h, t}$ is households' consumption, $H_{h, t}$ is the houses held by households, $j_{t}$ is housing preference, and $w_{t}$ is the wage rate. The first-order condition is:

$$
\frac{j_{t} C_{h, t}}{P_{t} H_{h, t}}=1-\beta \frac{C_{h, t}}{C_{h, t+1}} \cdot \frac{P_{t+1}}{P_{t}}
$$

Equation (10) shows that a household's acceptable house price is affected by the goods consumption: the faster the goods consumption increases, the faster the house price increases.

Assuming that enterprises are not allowed to buy houses, then households will hold all houses $\left(H_{h, t}=H\right)$, and the economy has a balanced growth path (henceforth BGP). The output growth rate, housing price growth rate, interest rate, saving rate, consumption, and capital investment are respectively:

ISSN: 0010-8189

(C) CONVERTER 2020 


$$
\begin{gathered}
g=g_{K}=g_{C_{e}}=g_{C_{h}}=\left(g_{A}\right)^{\frac{1}{1-\alpha}}\left(g_{L}\right) \\
g_{P}=g *\left(g_{j}\right) \\
r=\frac{g}{\beta} \\
s=\beta \\
C_{e, t}=(1-\beta) \alpha Y_{t} \\
C_{h, t}=(1-\alpha) Y_{t} \\
I_{t}=\beta \alpha Y_{t}
\end{gathered}
$$

2.2 The income effect, population effect, and urbanization effect

According to the growth theory, the long-term growth of per capita income can only come from technological progress or human capital accumulation. We use technology growth to reflect the income effect. The population effect is reflected by population growth, which will increase both the number of workers and the number of house buyers. The urbanization effect emphasis that housing demand growth under the condition of constant population and income, and we use the growth of housing preference (Iacoviello and Neri ${ }^{[6]}$ ) to reflect it.

\subsubsection{Income effect: $g_{A}>1, g_{L}=1, g_{j}=1$}

It's easy to show that the faster the technological growth rate is, the faster the housing price growth rate is. However, the technological progress increases the housing price growth rate and the interest rate at the same time, and does not break the condition of $r=\frac{g}{\beta}>g_{P}$. That means, income effect would increase housing price growth rate, but wouldn't trigger housing bubbles.

2.2.2 Population effect: $g_{A}=1, g_{L}>1, g_{j}=1$

The population effect works in the same way as the income effect: a rise in population growth increases housing price growth, but does not lead to housing bubbles.

\subsubsection{Urbanization effect: $g_{A}=1, g_{L}=1, g_{j}>1$}

The urbanization effect will only increase the housing price growth rate, not interest rates. It can be divided into two situations: when $g_{j}$ is small $\left(g_{j}<1 / \beta\right)$, the housing price growth rate is lower than the interest rate, and the bubbles wouldn't be triggered; when $g_{j}$ is large $\left(g_{j}>1 / \beta\right)$, the housing price growth rate will be higher than the interest rate, and if the housing investment of enterprises is not restricted, enterprises will invest in houses and result in housing bubbles.

\section{Extention: high-speed urbanization and housing bubbles}

This sector focuses on the development of housing bubbles triggered by the urbanization effect. For simplicity, we set population is fixed, and housing preference grows exogenously with $g_{j}>1 / \beta$.

The setting of households is the same as above. Enterprises have capital and researchers. They hire workers to produce intermediate goods, obtain capital gains and profits for goods consumption and capital investment. Final goods are competitive with the production function:

$$
Y_{t}=\left(L_{f}\right)^{1-\rho}\left(\sum_{i=1}^{A_{t}} X_{i, t}^{\rho}\right)
$$

ISSN: 0010-8189 
where $L_{f}$ is the labor in the final goods sector, which we normalise to $1 . A_{t}$ is the varieties of intermediate goods and represents the technology (Romer ${ }^{[10]}$ ). $X_{i, t}$ is the quantity of intermediate goods $i$, and $\rho$ reflects the substitution elasticity of different intermediate goods.

The varieties of intermediate goods are developed by researchers:

$$
A_{t+1}=A_{t} \delta\left(L R_{t}+1\right)
$$

where $\delta$ means R\&D efficiency, and $L R_{t}$ is the number of researchers. Researchers lease the patent of intermediate goods $i$ to a monopoly enterprise. According to the free entry conditions, the patent fees equal the profits of intermediate goods.

The production function of intermediate goods $i$ is:

$$
X_{i, t}=\left(K_{i, t}\right)^{\alpha}\left(L P_{i, t}\right)^{1-\alpha}
$$

where $K_{i, t}$ and $L P_{i, t}$ are capital and labor used in the production of intermediate goods $i$.

The optimizations of enterprises and households are the same as above, except that the first budget constraint (equation 3) for enterprises becomes:

$$
r_{t}\left(O K_{t}-H K_{t}\right)+w_{t} L_{r, t}-C_{e, t}-I_{t}=0
$$

Also, assuming that enterprises are not allowed to buy houses in BGP, then the numbers of researchers and workers are respectively: $L R_{t}=\frac{1-\rho}{1-\alpha \rho} L$ and $\sum_{i=1}^{A_{t}} L P_{i, t}=\frac{(1-\alpha) \rho}{1-\alpha \rho} L$, where $L=L R_{t}+\sum_{i=1}^{A_{t}} L P_{i, t}$, and the wages of researchers and workers are equal. The technological growth rate (the ratio of the current period to the previous period, i.e., $\left.g_{P}=P_{t} / P_{t-1}\right)$ is:

$$
g_{A}=\delta\left(\frac{1-\rho}{1-\alpha \rho} L+1\right)
$$

The output growth rate, housing price growth rate, interest rate, saving rate, consumption, and capital investment are the same as the benchmark model.

Assuming that the economy is in BGP during the period $t$, and from the beginning of period $t+1$ enterprises are allowed to buy houses. As enterprises' housing investment $\left(H K_{t}\right)$ rises, the interest rate grows faster than the housing price. Thus, an optimal housing investment would make the growth rate of housing prices equal the interest rate.

After enterprises' housing investment, the labor share of output is $(1-\alpha) \rho \cdot Y_{\tau}$, and the patent share is $(1-\rho)$. $Y_{\tau}$. Although the housing investment reduce the industrial output $Y_{\tau}$, the incomes of the two sectors change at the same rate, and the wages of workers and researchers change simultaneously, making the technological growth rate remains unchanged.

In any $\tau$ period $(\tau \geq t+1)$, if there is no housing investment from enterprises, the original output and original interest rate $\left(O Y_{\tau}\right.$ and $\left.O r_{\tau}\right)$ are determined by the savings at the end of the previous period:

$$
\begin{aligned}
& O Y_{\tau}=Y_{\tau-1}\left(g_{A}\right)^{1-\rho}\left(\frac{\alpha \rho+1-\rho}{\alpha \rho} \cdot r_{\tau-1} \cdot s_{\tau-1}\right)^{\alpha \rho} \\
& O r_{\tau}=\left(g_{A}\right)^{1-\rho}\left(\frac{\alpha \rho+1-\rho}{\alpha \rho} \cdot s_{\tau-1}\right)^{\alpha \rho-1}\left(r_{\tau-1}\right)^{\alpha \rho}
\end{aligned}
$$

If the enterprises invest in houses, and denote that the ratio of housing investment to total capital is $m_{\tau}=\frac{H K_{\tau}}{O K_{\tau}}$, then the real output and interest rate are:

$$
\begin{gathered}
Y_{\tau}=O Y_{\tau} \cdot\left(1-m_{\tau}\right)^{\alpha \rho} \\
r_{\tau}=O r_{\tau} \cdot\left(1-m_{\tau}\right)^{\alpha \rho-1}
\end{gathered}
$$

ISSN: 0010-8189 
According to enterprises' first-order conditions (equation 6), the goal for enterprises' housing investment is: $E_{e-b g, \tau}\left(\frac{P_{\tau+1}}{P_{\tau}}\right)=r_{\tau}$, where $E_{e-b g, \tau}$ is enterprises' adaptive expectations at the beginning of $\tau$ :

$$
E_{e-b g, \tau}\left(\frac{P_{\tau+1}}{P_{\tau}}\right)=\frac{P_{\tau}}{P_{\tau-1}}
$$

After households sell houses, their consumptions and house holdings are:

$$
\begin{gathered}
C_{h, \tau}=(1-\alpha) \rho \cdot O Y_{\tau} \cdot\left(1-m_{\tau}\right)^{\alpha \rho}+O K_{\tau} m_{\tau} \\
H_{h, \tau}=H_{h, \tau-1}-\frac{O K_{\tau} m_{\tau}}{P_{\tau}}
\end{gathered}
$$

According to households' first-order conditions (equation 10), the goal for selling houses is:

$$
E_{h-b g, \tau}\left(\frac{P_{\tau+1}}{P_{\tau}}\right)=\left(1-\frac{j C_{h, \tau}}{P_{\tau} H_{h, \tau}}\right) \cdot \frac{1}{\beta} \cdot E_{h, \tau}\left(\frac{C_{h, \tau+1}}{C_{h, \tau}}\right)
$$

where $E_{h-b g, \tau}$ is the adaptive expectations of households at the beginning of period $\tau$ :

$$
\begin{gathered}
E_{h-b g, \tau}\left(\frac{P_{\tau+1}}{P_{\tau}}\right)=\frac{P_{\tau}}{P_{\tau-1}} \\
E_{h-b g, \tau}\left(\frac{C_{h, \tau+1}}{C_{h, \tau}}\right)=\frac{C_{h, \tau}}{C_{h, \tau-1}}
\end{gathered}
$$

Using equations 23-32, we can figure out $m_{\tau}, P_{\tau}$, and $Y_{\tau}$. At the end of period $\tau$, enterprises' saving decisions satisfy the Euler equation (equation 7): $E_{e-e n d, \tau}\left(\frac{C_{e, \tau+1}}{C_{e, \tau}}\right)=\beta r_{\tau+1}$, where $E_{e-e n d, \tau}$ is enterprises' adaptive expectations at the end of $\tau$. Drawing on the ideas of Glaeser et al. (2008), the individual predicts that there will be the same house purchasing and saving decisions in the next period, that is $E_{e-e n d, \tau}\left(s_{\tau+1}\right)=s_{\tau}, E_{e-e n d, \tau}\left(m_{\tau+1}\right)=$ $m_{\tau}$. The savings rate can be obtained by combining the above equations:

$$
s_{\tau}=\frac{\beta \alpha \rho}{(\alpha \rho+1-\rho) \cdot\left(1-m_{\tau}\right)}
$$

Equation 26 and 33 show that the interest rate and saving rate get a rise after enterprises' housing investment. Consumption in the current period and total capital in the next period are:

$$
\begin{gathered}
C_{h, \tau}=(1-\alpha) \rho \cdot Y_{\tau}+O K_{\tau} m_{\tau} \\
C_{e, \tau}=(1-\rho+\alpha \rho) \cdot Y_{\tau} \cdot\left(1-s_{\tau}\right) \\
O K_{\tau+1}=(1-\rho+\alpha \rho) \cdot Y_{\tau} \cdot s_{\tau}
\end{gathered}
$$

In any $\tau$ period $(\tau \geq t+1)$, as long as the original housing price growth rate is higher than the original interest rate, enterprises will keep buying houses. When the original housing price growth rate is lower than the interest rate, enterprises will stop buying houses, which causes a decline in the growth rate of household consumption, thereby lowering households' willingness housing prices. That further reduces enterprises' housing price expectations, causing enterprises to sell houses. Then the housing bubbles will burst.

Assuming that at the beginning of any $\tau+1$ period $(\tau \geq t+1)$, the growth rate of the initial house price is lower than the interest rate. We still denote the ratio of the house sales to the total capital as $m_{\tau+1}$ :

Household consumption and housing prices meet:

$$
m_{\tau+1}=-P_{\tau+1} H_{e, \tau} / O K_{\tau+1}
$$

$$
\begin{gathered}
C_{h, \tau+1}=(1-\alpha) \rho \cdot Y_{\tau+1} \cdot\left(1-m_{\tau+1}\right)^{\alpha \rho}+O K_{t+1} m_{t+1} \\
\frac{P_{\tau+1}}{P_{\tau}}=\left(1-\frac{j C_{h, \tau+1}}{P_{\tau+1} H}\right) \frac{1}{\beta} \frac{C_{h, \tau+1}}{C_{h, \tau}}
\end{gathered}
$$

ISSN: 0010-8189 
We can derive the housing price and output with the above three equations at the bubble-bursting period. Then the process of bubbles in a full cycle has been described.

\section{Simulation}

We simulate the evolution of housing bubbles at different speeds of urbanization, as shown in Figure 2 below. Period 1 is in BGP, and enterprises are allowed to buy houses from period 2. The dotted lines are the cases where enterprises are not allowed to buy houses, and are added for comparison.

The simulation shows that: 1) even if the housing preference continues to grow, the housing bubbles can not expand permanently, and the bubble burst is an inevitable result; 2) the higher the growth rate of housing preference, the longer the bubble period, and the greater the impact on the economy after the bubble bursts; 3) with a higher growth rate of housing preference, the growth rate of housing price is higher, and enterprises' consumption and the houses held by households are less. The output and household consumption are less affected by bubbles. The bubbles raise the interest rate and the saving rate, and the rising saving rate makes up for the decline in productive investment. The small impact on household consumption is that the income from selling houses offsets the decline in wages, and increases the total consumption.

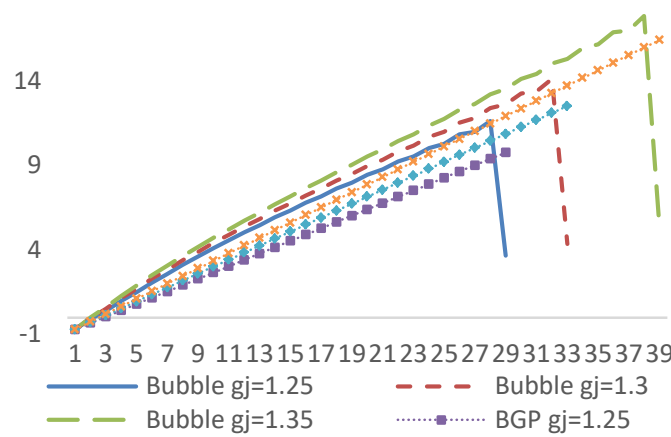

Fig 2.a: Housing Price

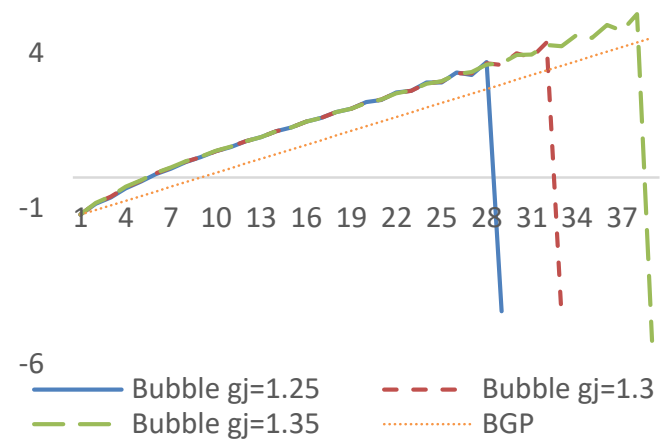

Fig 2.c: Households goods consumption

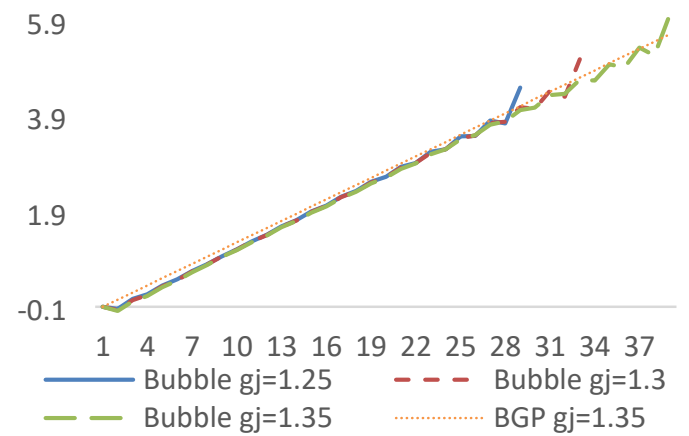

Fig 2.b: Final Output

2

$-3$

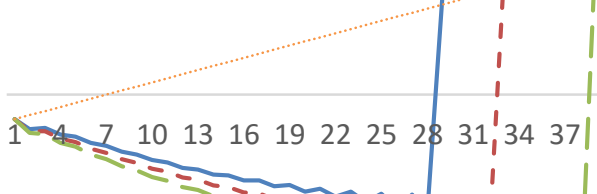

$-8$

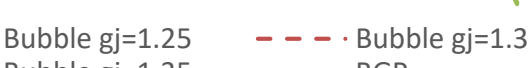

- Bubble gj=1.35 ……….... BGP

Fig 2.d: Enterprises goods consumption

ISSN: 0010-8189 


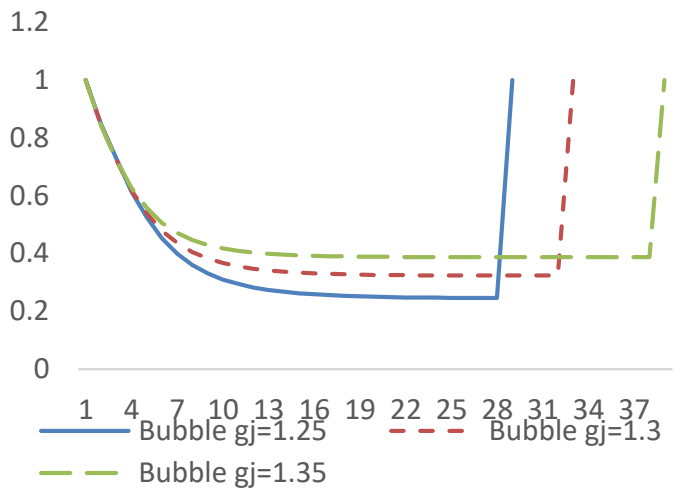

Fig 2.e: Houses held by households

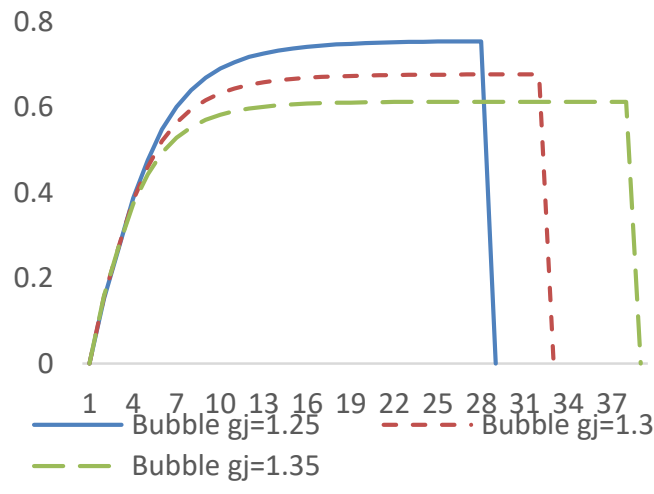

Fig 2.f: Houses held by enterprises

Values of parameters: $\alpha=0.5, \rho=0.6, \beta=0.99, g_{A}=1.3, Y_{1}=H=1, P_{1}=0.5$

Fig 2: Housing bubbles in the benchmark model

In reality, the urbanization effect can't grow at high speed permanently. It is more likely that after high-speed urbanization for a while, the growth rate declined. If household demand for houses stops growing after causing a bubble, will the bubble burst immediately?

Figure 3 below simulates the situation where the duration of high-speed urbanization is limited. In the figure below, $T_{j}=10$ and $T_{j}=20$ indicate that the growth of $g_{j}$ stops after the 10th and 20th periods respectively, and the case of permanent $g_{j}$ growth $\left(T_{j}=100\right)$ is used as a comparison. The simulation results show that: (1) The earlier the urbanization ends, the shorter the bubble cycle, and the smaller the impact on the economy after the bubble burst. (2) After the urbanization stopped, the bubble did not burst immediately, but continued to develop for a long time.

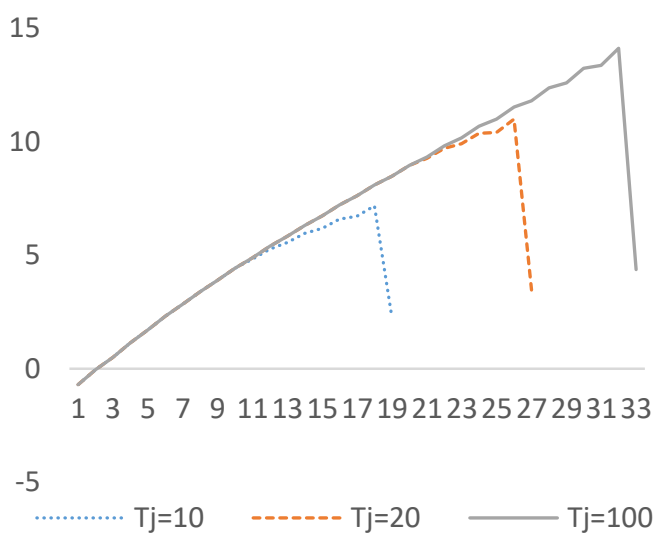

Fig 3.a: Housing Price

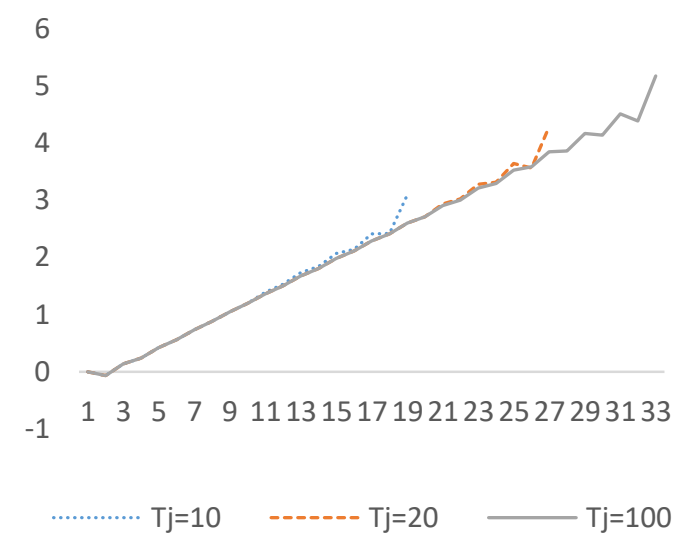

Fig 3.b: Final Output

ISSN: 0010-8189 
6

4

2

0 $-2$

$-4$

$-6$

$-8$

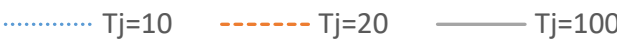

Fig 3.c: Households goods consumption

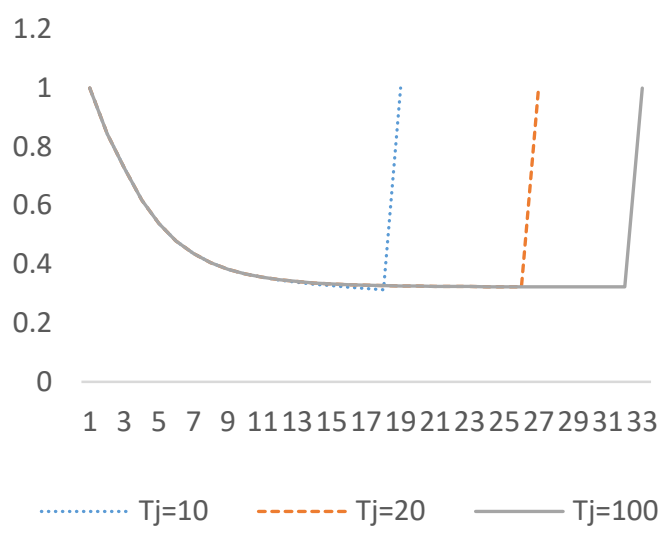

Fig 3.e: Houses held by households

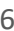

4

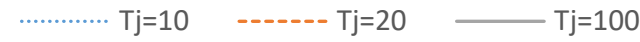

Fig 3.d: Enterprises goods consumption

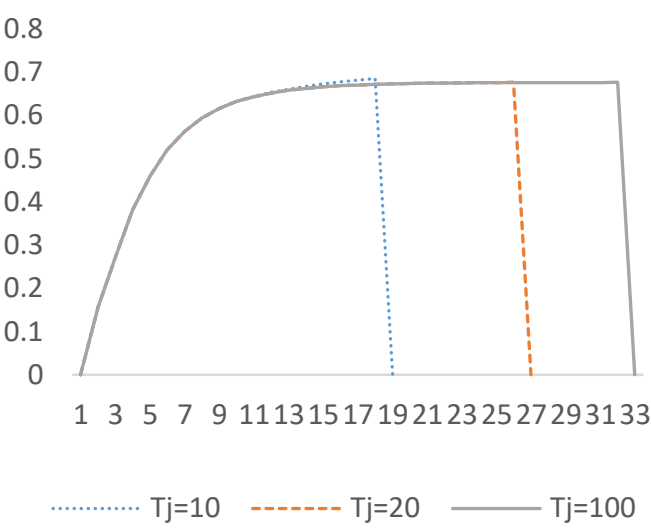

Fig 3.f: Houses held by enterprises

Values of parameters: $\alpha=0.5, \rho=0.6, \beta=0.99, g_{A}=1.3, Y_{1}=H=1, P_{1}=0.5$

Fig 3: Housing bubbles in the extention model

\section{Conclusion}

We put forward a multi-sector optimization method under short-term decisions, and used the method to analyze housing bubbles caused by the rapid urbanization in China. The model simulates the way households and enterprises make decisions when bubbles are inflating, as well as the evolution of production, consumption, saving and housing price. We show that if bubbles are driven by adaptive expectations, they can exist without credit constraints, and burst without exogenous probability distributions or shocks.

\section{Acknowledgements}

This research was supported was supported by the Science and Technology Department of Henan Province, China (Grant No. 192400410381).

\section{References}

[1] Arce, Óscar, David López-Salido, "Housing bubbles," American Economic Journal: Macroeconomics, vol. 3, no.1, pp. 212-41, 2011.

[2] Farhi, Emmanuel, Jean Tirole, "Bubbly liquidity," The Review of Economic Studies, vol. 79, no. 2, pp. 678-706, 2012.

[3] Glaeser, L. Edward, G. Joseph, S. Albert, "Housing supply and housing bubbles," Journal of urban

ISSN: 0010-8189 
Economics, vol. 64, no. 2, pp. 198-217, 2008.

[4] Grossman, M. Gene, Y. Noriyuki, "Asset bubbles and endogenous growth," Journal of Monetary Economics, vol. 31, no. 1, pp. 3-19, 1993.

[5] Herring, J. Richard, M. Susan, Wachter, "Real estate booms and banking busts: An international perspective," The Wharton School Research Paper, PP. 99-27, 1999.

[6] Iacoviello, Matteo, N. Stefano, "Housing market spillovers: evidence from an estimated DSGE model," American Economic Journal: Macroeconomics, vol. 2, no. 2, pp. 125-64, 2010.

[7] Kiyotaki, Nobuhiro, M. John, "Liquidity, business cycles, and monetary policy," Journal of Political Economy, vol. 127, no. 6, pp. 2926-2966, 2019.

[8] Malpezzi, Stephen, W. Susan, "The role of speculation in real estate cycles," Journal of Real Estate Literature, vol. 13, no. 2, pp. 141-164, 2005.

[9] J.J. Miao, P.F. Wang, "Bubbles and total factor productivity," American Economic Review, vol. 102, no. 3, pp. 82-87, 2012.

[10] Romer, M. Paul, "Endogenous technological change," Journal of political Economy, vol. 98, no. 5, Part 2, pp. S71-S102, 1990.

[11] Santos, S. Manuel, W. Michael, "Rational asset pricing bubbles," Econometrica: Journal of the Econometric Society, PP. 19-57, 1997.

[12] B. Zhao, "Rational housing bubble," Economic Theory, vol. 60, no. 1, pp. 141-201, 2015. 